\title{
FACTORS FOR USER INTENTION TO SWITCH BROWSERS: A CROSS-NATIONAL SURVEY
}

\author{
Chian-Son Yu \\ Shih Chien University \\ csyu@g2.usc.edu.tw \\ Wachara Chantatub \\ Chulalongkorn Business School, Chulalongkorn University \\ wachara@cbs.chula.ac.th \\ Basak Mendi \\ Istanbul Bilim University, Istanbul, Turkey \\ basak.mendi@istanbulbilim.edu.tr
}

\begin{abstract}
Because web browsers offer essential Internet-based services with no clear profit model and no registration or login requirements, this empirical study examined the factors influencing user intention to switch Internet browsers. Through the cross-national survey, this study found neither satisfaction nor familiarity significantly influences switching intention among respondents in any country, whereas experience, attraction, and preference considerably influenced the switching intention of users in all three countries. Attracting new users to a web browser relies on attractiveness, but retaining those users relies on a positive experience. The results of this study suggested that web browser use is highly ingrained in daily routines because of user preferences, and that user preferences create habits that form daily routines. This study also observed contextual effects that have already been extensively discussed.
\end{abstract}

Keywords: Web Browser Service, Online Service, Consumer Switching Intention, Push-Pull-Mooring (PPM)

\section{INTRODUCTION}

Every day, billions of people use the Internet for seeking information, uploading data or photos, sharing or sending opinions, downloading or receiving messages, watching videos or webcasting, learning, shopping, 
playing games, and checking social media. As of December 2016, more than 3.68 billion people (50.2\% of the world population) had used the Internet. ${ }^{1}$ Web browsers are distinct from other Internet-based services, such as Internet portals, shopping websites, search engines, blogs, e-learning platforms, social networking sites (SNSs), video sharing websites, microblogging platforms, and cloud-based gaming websites. Web browsers are free services that do not require registration and login; moreover, browsing service providers do not know who uses their services. Although other Internet-based services are not essential, they have clear commercial models. In contrast, web browsers offer essential services but lack a clear profit model.

Although the Internet has provided abundant commercial opportunities to numerous Internet-based services, web browsers are a tool, a mediation platform, or a channel for delivering or accessing online services. Accordingly, academic researchers have paid considerable attention to Internet portals, shopping websites, search engines, blogs, SNSs, video sharing websites, online banking, cloud-based gaming websites, and broadcasting. Few academic researchers have studied web browsers. Most studies have examined users' switching intention and behavior related to Internet-enabled services, but only one study has investigated the factors affecting user intention to continue using or switch web browsers. ${ }^{2}$

The competition among web browsers is as intense as that for other Internet-based service markets. ${ }^{3}$ For examples, Netscape Navigator was widely popular at its peak period, but eventually shut down; Microsoft Internet Explorer dominated the market for several years, but later withdrew from the market. Despite attempting to regain lost users by introducing Microsoft Edge to replace Internet Explorer, Microsoft lost over 300 million in $2016 .^{4}$ The intense competition in the global web browser market causes variations in market shares and rankings across countries and over years or even months. For example, Mozilla Firefox has been the top desk web browser in Germany for several years, Microsoft dominated the browser markets of Japan and Korea for over a decade, and Opera has dominated the markets of most African countries. ${ }^{5}$ In global market share, Google Chrome surpassed Microsoft Internet Explorer in early 2012, and Apple Safari exceeded Mozilla Firefox in mid-2014. ${ }^{6}$

Given that acquiring new customers for online service providers is expensively as well as retaining existing customers and preventing them from switching to competitive offerings is more difficult in the online environment than in the offline environment, considerable research has been conducted on commercial Internet-based services. When comparing only one study on web browsers with abundant research on Internet portals, 
shopping websites, search engines, blogs, e-learning platforms, SNSs, microblogging platforms and online-gaming platforms, this study advances the knowledge of the factors that affect users' continued use of a web browser or their intention to switch from one web browser to another. In this study, respondents were recruited from Turkey, Thailand, and Taiwan. The remainder of this paper is organized as follows. Section 2 reviews the literature and theory; Section 3 presents the hypotheses, questionnaire and sampling; Section 4 describes data analysis and implications; Section 5 discusses the findings; and Section 6 presents the conclusion and limitations of this study.

\section{LITERATURE REVIEW AND THEORETICAL BASIS}

Keaveney ${ }^{7}$ provides the foundation for a systematic investigation of consumer switching behavior among service providers. Prior to Keaveney's study $^{7}$, research on service provider switching was limited to models of satisfaction with service quality. Keaveney and Parthasarathy ${ }^{8}$ conducted the earliest study of online service switching behavior, in which they contended that two attitudinal variables (satisfaction and service quality) significantly influenced customer switching intentions. In addition, they characterized the information that customers used when making decisions as internal versus external, personal versus impersonal, and marketer-oriented versus third-party.

By examining 2,920 unique users from 2,257 households using online broker services, Chen and $\mathrm{Hitt}^{9}$ revealed that $55.7 \%$ were active and remained with their original broker, $10.6 \%$ switched, and the remaining $33.7 \%$ were inactive. Their study concluded that switching cost and the ability to develop customer loyalty were the main drivers of success in the online services industry. Kim et al. ${ }^{10}$ recruited 1408 respondents to investigate user-switching between email service providers. Their empirical results indicated that attractive alternatives, and to a lesser extent switching cost and customer satisfaction significantly affected a customer's intention to switch email service providers. For customer satisfaction, system stability, storage capacity, and spam blocking were significant variables influencing the intention to switch.

By realizing the necessity and importance of investigating why some consumers remain with a website, but others do not, Li et al. ${ }^{11}$ surveyed 299 samples (158 stayers and 141 switchers). By examining the differences between stayers and switchers based on an integrated buyer-seller relationship model, they concluded that stayers were more committed to online businesses, had greater trust in online businesses, and were more 
satisfied with online businesses that switchers were. In contrast to Kim et al.'s ${ }^{10}$ finding that attractive alternatives are the most influential factor, Li et al. ${ }^{11}$ found that satisfaction is the most influential factor in distinguishing switchers from stayers.

By citing the marketing literature, Zengyan et al. ${ }^{12}$ used Push-Pull-Mooring (PPM) theory to construct hypotheses examining the factors in user intention to switch among SNSs. Their empirical results indicated that both push and pull factors substantially affected user intention to switch, while mooring factors did not play a salient role. Among push factors, dissatisfaction with member policy held the largest influence; peer influence was the most crucial of the pull factors. Hou et al. ${ }^{13}$ discovered that research on customer switching behavioral intentions fell into three streams: (1) understanding consumer switch processes; (2) examining the heterogeneous characteristics of stayers and switchers; and (3) exploring factors that drive customers to switch. The third stream has attracted the greatest attention.

Consequently, Hou et al. ${ }^{13}$ adapted the PPM migration model from the migration literature to investigate the game-player switching intentions among game portal websites. By surveying 167 respondents, Hou et al. ${ }^{13}$ concluded that mooring effects were the strongest drivers of switching intentions. Pulling effects (measured by the degree of enjoyment, pricing, and service quality) substantially affected switching intentions. However, push effects were not a significant factor in affecting game-player switching intentions. Given the lack of research on post-adoption switching among personal services (i.e., web search engines and browsers), Ye and Potter ${ }^{2}$ used the PPM model to investigate factors influencing individual switching choices among web browsers. After collecting 414 usable student samples through an online survey, Ye and Potter $^{2}$ concluded that push effects, pull effects, mooring effects, and habit significantly influenced intention to switch, and that mooring effects considerably moderated the relationships between pull effects and intention to switch.

Due to a surprising lack of research on auction-seller intention to switch from one auction website to another, Lin et al. ${ }^{14}$ studied what convinces auction sellers to switch to competing providers who offer the same services, how anti-lock-in initiatives in an auction platform induce auction sellers to switch, and whether network effects affect auction-seller switching intentions. Based on the case of Yahoo!Kimo versus Reten_eBay, their research summarized the factors influencing auction-seller switching intention among competing platforms. By examining 292 samples from sellers, Lin et al. ${ }^{14}$ discovered that switching costs, transaction fees, website quality, and anti-lock-in significantly affected auction-seller intentions to 
switch. Their study indicated that switching costs and transaction fee were the two most influential of these factors, and that the information quality of Yahoo!Kimo and Reten_eBay was similar to auction sellers.

Zhang et al. ${ }^{15}$ argued that switching behavior generates negative effects on online service providers and long-term relationships bring substantial profitability to firms. By observing that online service providers contend with the same challenge of maintaining their users and preventing them from switching to other providers, Zhang et al. ${ }^{15}$ attempted to clarify online service switching behavior by investigating why users switch their blog service providers. By gathering 299 usable responses from Hong Kong bloggers, Zhang et al. ${ }^{15}$ discovered that the push factor (satisfaction) and the mooring factor (sunk cost) negatively affected blogger intention to switch (at $p$-value $<0.001$ ) and the pull factor (attractive alternative) increased blogger intention to switch (at $p$-value $<0.05$ ).

By summarizing prior literature pertaining to post-adoption behaviors and consumer switching behaviors, Hsieh et al. ${ }^{16}$ proposed a PPM model to delineate the determinants of substitution of online services. Based on PPM framework, they developed a model with six hypotheses. By drawing 319 bloggers aged 18-35 from an online survey, they applied partial least squares (PLS) techniques to examine the hypotheses and the proposed model's robustness. Hsieh et al. ${ }^{16}$ discovered that both push and pull effects had positive influences on bloggers' switching intention, while the mooring effect had negative influence and moderating effect on bloggers' switching intention.

Considering that the switching behavior of SNS users is yet to be explored to gain new knowledge and practical suggestions, Wu et al. ${ }^{17}$ employed a higher-level research model and lower-level switching pattern drill-down analysis to explore the actual switching behavior of SNS users. Based on 343 valid questionnaires, their study found that switching barrier held an extremely significant influence (at $p$-value $<0.001$ ) and satisfaction had a slight significant influence (at $p$-value $<0.05$ ). Switching barrier was incurred from switching cost, and satisfaction came from service quality of SNS. Wu et al. ${ }^{17}$ concluded that better service quality resulted in higher satisfaction and higher switching costs increased user's switching barriers. Therefore, high switching barriers and satisfaction are key factors in retaining current SNS users.

Because the Internet has produced a variety of online services, $\mathrm{Liu}^{18}$ considered that understanding consumer online service switching intention is essential to gaining a competitive advantage. By reviewing the literature on e-trading of securities, e-service quality, perceived value, e-satisfaction, 
e-trust, and switching intention, Liu $^{18}$ posited eight hypotheses. By analyzing 515 acceptable responses via structural equation modeling (SEM) analysis, Liu found that perceived value and e-satisfaction significantly affected consumer switching intention (at $p$-value $<0.05$ ) and e-trust considerably influenced consumer switching intention (at $p$-value $<0.001$ ) from one e-trading platform to another.

Upon reviewing the literature, we learned that online services resemble offline services in the sense that there are many competing service providers and alternatives on the market. In other words, consumers can easily find and choose substitutes because of the similar (or even identical) features and functionalities offered. Keaveney and Parthasarathy ${ }^{8}$ referred to this type of competition as churn. Churn can be fluid in a rapidly changing market and is a crucial concern for online service providers. The literature review also reveals the following conflicting and inconsistent findings.

Zengyan et al. ${ }^{12}$ concluded that mooring factors did not influence user intention to switch, but Hou et al. ${ }^{13}$ argued that mooring effects are the strongest drivers of switching intentions. Ye and Potter ${ }^{2}$ and Zhang et al. ${ }^{15}$ found that push effects, pull effects and mooring effects are all significant factors influencing switching intention, while Zengyan et al. ${ }^{12}$ and Hou et al. ${ }^{13}$ contended that only two of the three are. Kim et al. ${ }^{10}$ discovered attractive alternatives to have the most powerful influence on customer intention to switch, while $\mathrm{Li}$ et al. ${ }^{11}$ found satisfaction to be the most influential factor. Zhang et al. ${ }^{15}$ considered functionality and ease-of-use as two important factors, whereas Chen and $\mathrm{Hitt}^{9}$ argued ease-of-use and website personalization exert no effect. Zhang et al. ${ }^{15}$ included subjective norms as a mooring factor, while Zengyan et al. ${ }^{12}$ included peer influence among the pull factors. Hou et al. ${ }^{13}$ deemed service quality as belonging to the pull effect, whereas Zhang et al. ${ }^{15}$ considered service quality as belonging to the push effect.

Although most studies have focused on the adoption of a specific technological service or product, few studies noted the importance of understanding the transition between technological services or products. Therefore, investigations of what influences people to transition from one technological service to a similar one has increased over the past decade. This literature review shows that there are two streams of research regarding online users' post-adoption behavior: one explores adoption continuance by using theories of technology adoption ${ }^{19,20,21,22}$, and the other examines investigating consumer switching behavior by using PPM theory ${ }^{2,13,15,16,23,24}$. Considering that adoption is not synonymous with continuous use ${ }^{25,26}$, researchers have constructed their research models based on theories of technology adoption. ${ }^{14,19,20,21,22}$ Literature indicates that the technology 
acceptance model (TAM), theory of planned behavior (TPB) and expectation-confirmation theory (ECT) were extended to investigate continued adoption.

Both streams provide key insights into why users remain with a service provider or switch to another. In this study, we selected PPM instead of theories of technology adoption for three reasons. The first reason is that when users switch from one service provider to another, they have moved beyond the initial adoption phase and have experience using the service. In addition, when competitive alternatives exist in the market, the users' switching behavior itself cannot be easily classified into a continuance versus discontinuance perspective because they may use both services at the same time. For example, the users mainly use Line (regular users) and occasionally use WeChat (sparse users). Finally, theories of technology adoption were originally developed to understand whether people are willing to adopt a specific technological service or product. When users switch, it does not imply that they stop using that service or product. In reality, they only favor an alternative while continuing using the service or product. These observations may explain why the PPM is the most used theory in the context of online service ${ }^{2,13,15,16,23}$, and is a theory that has been applied to study consumer switching behavior in a variety of business research areas. ${ }^{24}$

\section{HYPOTHESES, QUESTIONNAIRE AND SAMPLING}

The concept of PPM is traceable to the $1880 \mathrm{~s} .{ }^{27}$ After being modified several times, PPM has become a dominant paradigm in migration literature $^{12,15,20}$ and has been considered superior to other models of consumer switching behavior. ${ }^{12}$ Accordingly, PPM is used here as a theoretical foundation of the research structure. In the PPM framework, three factors affect migration decisions to move from a one living environment to another: push, pull and mooring.

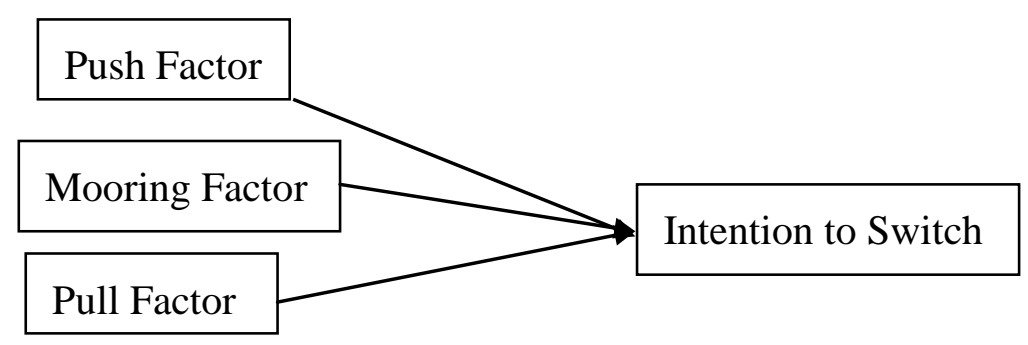

Figure 1. The PPM Structure adapted from Zhang et al. ${ }^{15}$ 


\subsection{The Push Factor}

In the PPM framework, push factors drive people away from their original location. By reading industry reports, Keaveney and Parthasarathy ${ }^{8}$ learned that online service providers compete in a rapidly changing market and identified that continuers exhibited greater satisfaction and involvement than did switchers, based on their second empirical results. By recruiting 1408 respondents to investigate user-switching between email service providers, Kim et al. ${ }^{10}$ found that customer satisfaction significantly affected a customer's intention to switch email service providers. By examining 158 stayers and 141 switchers, $\mathrm{Li}$ et al. ${ }^{11}$ concluded that satisfaction is the most influential factor in distinguishing switchers from stayers. Similarly, in the context of bloggers' switch intention, Zhang et al. ${ }^{23}$ and Zhang et al. ${ }^{15}$ considered satisfaction as the important factor; in the case of switching intention among SNSs, Zengyan et al. ${ }^{12}$ and $\mathrm{Wu}$ et al. ${ }^{17}$ concluded that satisfaction holds significant influence for retaining current users. Accordingly, following the previous literature $2,10,11,12,13,15$, we used "satisfaction of using current web browser" to assess the push factor. As a result, the following hypothesis is posited:

H1: The satisfaction with a web browser significantly influences consumer intention to switch browsers.

\subsection{The Mooring Factor}

In the PPM framework, mooring factors are the personal, social, cultural and situational factors that either facilitate or hamper migration decisions. ${ }^{12,13,15,28,20}$ Conceptually, mooring factors are the situational or contextual factors that influence migration intention. ${ }^{24}$ Literature review indicates that sunk cost, ${ }^{15,23}$ switching cost ${ }^{9,10,14,17}$ or switching barrier ${ }^{29}$ are most used to assess mooring factors. However, in a focus group and panel discussion of six Internet users and four scholars to assess the mooring factor, everyone agreed that web browsers are free, they have little to no switching cost or lock-in effect, and people can use switching in fingertips. Thus, browsers are characterized by high substitutability and low differentiation, and possess only slight brand name value. In contrast, preference, familiarity and past experience are main factors that influence people to use one browser rather than another. The literature review showed that preference ${ }^{24}$, familiarity ${ }^{2}$ and past experience ${ }^{16}$ are also frequently used in PPM research. ${ }^{2,8,10,12,15}$ Considering the features of web browser service and according to the consensus of the focus group, we used users' preferences, familiarities, and experiences to assess the mooring factor. As a result, the following hypotheses are proposed: 
H2: The preference for using the web browser significantly influences consumer switching intention among browsers.

H3: The familiarity with the web browser significantly influences consumer switching intention among browsers.

H4: The experience with the web browser significantly influences consumer switching intention among browsers.

\subsection{The Pull Factor}

In the PPM framework, pull factors attract people to a new place. Because pull factors draw prospective migrants to the destination, attractiveness of alternatives is the most widely used to evaluate the pull factor. ${ }^{13,15,23,30,31}$ After collecting 229 usable samples in Hong Kong, Zhang et al. ${ }^{23}$ found that attractiveness of alternatives has the largest influence on bloggers' switching behavior. Their finding is consistent with that of Kim et al. ${ }^{10}$. Meanwhile, by surveying 654 online gamers, Hou et al. ${ }^{13}$ found that attractiveness of alternatives affects people to switch online games but its influence is less than mooring factor and push factor. Similarly, Zhang et al. ${ }^{15}$ analyzed 299 usable questionnaires and concluded that attractiveness of alternatives has the most influence on online service switching intention. The conclusions of Hou et al. ${ }^{13}$ and Zhang et al. ${ }^{15}$ are consistent to that of $\mathrm{Li}$ et al. ${ }^{11}$. By sampling 580 Jordanian mobile users, Awwad and Neimat ${ }^{30}$ identified attractiveness of alternatives as the second strongest factor in the switching behavior of mobile service users. Obviously, although the literature showed that the strength of pull factor varies across the contexts, attractiveness of alternatives is widely used to assess the pull factor. This leads to the following hypothesis:

H5: The attraction for using the web browser significantly influences consumer switching intention among browsers.

\subsection{Questionnaire and Sampling}

To achieve the research goal and assess the research constructs, the 30-item questionnaire was developed through a secondary literature review, three expert-user meetings, and a pretest. The stages are described below. In the first stage, 24 items that access six constructs were initially culled from the related literature. ${ }^{2,15,10,11,12,13,17}$ In the second stage, these items were reworded to fit the context of web browser-switching intention by three meetings of expert users in Turkey, Taiwan, and Thailand. After checking and verifying the study's research structure and hypothesis, one question was added to ask respondents which browser they used the most and five questions were added to collect the respondents' demographic data. 
The third stage is a small-scale user pretest. Thirty students who are regular Internet users were invited to fill out the paper questionnaire. Twenty-four questions assessing six constructs were evaluated on a five-point Likert scale ranging from 1 (strongly disagree) to 5 (strongly agree). Accordingly, the final version of the questionnaire items was divided into three sections as shown in the Appendix. In contrast to studies that been limited to college students aged 18-22, this research diversified its respondents by advertising the survey on dozens of blog websites. Considering the balance of time, effectiveness, and limited resources, we set a two-month survey period to collect data via online survey. Therefore, the sample size varies across countries and three group's sizes may not reflect the proportion of each country's population. The questionnaire was posted on each country's most popular online survey websites. Table 1 presents a brief profile of the respondents 1 .

Table 1. Basic data of the Turkish, Taiwanese, and Thai respondents

\begin{tabular}{|c|c|c|c|c|}
\hline & \multirow[t]{2}{*}{ Categories } & \multicolumn{3}{|c|}{$\begin{array}{c}\text { Number of Respondents } \\
\text { Percentage }\end{array}$} \\
\hline & & Turkey & Taiwan & Thailand \\
\hline \multirow{2}{*}{ Gender } & Male & $\begin{array}{c}154 \\
51.2 \% \\
\end{array}$ & $\begin{array}{c}172 \\
50.9 \% \\
\end{array}$ & $\begin{array}{c}133 \\
55.4 \% \\
\end{array}$ \\
\hline & Female & $\begin{array}{c}147 \\
48.8 \%\end{array}$ & $\begin{array}{c}166 \\
49.1 \%\end{array}$ & $\begin{array}{c}107 \\
44.6 \%\end{array}$ \\
\hline \multirow{11}{*}{ Age } & Less than 20 years old & $\begin{array}{c}0 \\
0.0 \%\end{array}$ & $\begin{array}{c}18 \\
5.3 \% \\
\end{array}$ & $\begin{array}{c}3 \\
1.3 \% \\
\end{array}$ \\
\hline & 20-25 years old & $\begin{array}{c}54 \\
17.9 \% \\
\end{array}$ & $\begin{array}{c}60 \\
17.8 \% \\
\end{array}$ & $\begin{array}{c}28 \\
11.7 \% \\
\end{array}$ \\
\hline & 25-30 years old & $\begin{array}{c}81 \\
26.9 \% \\
\end{array}$ & $\begin{array}{c}92 \\
27.2 \% \\
\end{array}$ & $\begin{array}{c}98 \\
40.8 \% \\
\end{array}$ \\
\hline & 30-35 years old & $\begin{array}{c}47 \\
15.6 \% \\
\end{array}$ & $\begin{array}{c}38 \\
11.2 \% \\
\end{array}$ & $\begin{array}{c}70 \\
29.2 \% \\
\end{array}$ \\
\hline & $35-40$ years old & $\begin{array}{c}42 \\
14.0 \% \\
\end{array}$ & $\begin{array}{c}18 \\
5.3 \% \\
\end{array}$ & $\begin{array}{c}19 \\
7.9 \% \\
\end{array}$ \\
\hline & 40-45 years old & $\begin{array}{c}19 \\
6.3 \%\end{array}$ & $\begin{array}{c}26 \\
7.7 \%\end{array}$ & $\begin{array}{c}10 \\
4.2 \%\end{array}$ \\
\hline & $45-50$ years old & $\begin{array}{c}10 \\
3.3 \%\end{array}$ & $\begin{array}{c}30 \\
8.9 \%\end{array}$ & $\begin{array}{c}3 \\
1.3 \%\end{array}$ \\
\hline & $50-55$ years old & $\begin{array}{c}7 \\
2.3 \% \\
\end{array}$ & $\begin{array}{c}16 \\
4.7 \% \\
\end{array}$ & $\begin{array}{c}3 \\
1.3 \% \\
\end{array}$ \\
\hline & $55-60$ years old & $\begin{array}{c}11 \\
3.7 \% \\
\end{array}$ & $\begin{array}{c}20 \\
5.9 \% \\
\end{array}$ & $\begin{array}{c}2 \\
0.8 \% \\
\end{array}$ \\
\hline & $60-65$ years old & $\begin{array}{c}18 \\
6.0 \% \\
\end{array}$ & $\begin{array}{c}18 \\
5.3 \% \\
\end{array}$ & $\begin{array}{c}2 \\
0.8 \% \\
\end{array}$ \\
\hline & above 65 years old & $\begin{array}{c}12 \\
4.0 \%\end{array}$ & $\begin{array}{c}2 \\
0.6 \%\end{array}$ & $\begin{array}{c}2 \\
0.8 \%\end{array}$ \\
\hline
\end{tabular}


Table 1. Basic data of the Turkish, Taiwanese, and Thai respondents (con.)

\begin{tabular}{|c|c|c|c|c|}
\hline & \multirow[t]{2}{*}{ Categories } & \multicolumn{3}{|c|}{$\begin{array}{c}\text { Number of Respondents } \\
\text { Percentage }\end{array}$} \\
\hline & & Turkey & Taiwan & Thailand \\
\hline \multirow{9}{*}{ Education } & \multirow[t]{2}{*}{ High School or Below } & $\begin{array}{c}8 \\
7 \%\end{array}$ & 15 & 3 \\
\hline & & $2.7 \%$ & $4.4 \%$ & $\frac{1.3 \%}{5}$ \\
\hline & Associate Bachelor Degree & $\begin{array}{c}13 \\
4.3 \%\end{array}$ & $\begin{array}{c}46 \\
13.6 \%\end{array}$ & $\begin{array}{c}5 \\
2.1 \%\end{array}$ \\
\hline & \multirow{2}{*}{ Bachelor Degree } & 194 & 168 & 156 \\
\hline & & $64.5 \%$ & $49.7 \%$ & $65.0 \%$ \\
\hline & \multirow{2}{*}{ Master Degree } & 58 & 91 & 74 \\
\hline & & $19.3 \%$ & $26.9 \%$ & $30.8 \%$ \\
\hline & \multirow{2}{*}{ Ph.D. Degree } & 28 & 18 & 2 \\
\hline & & $9.3 \%$ & $5.3 \%$ & $0.8 \%$ \\
\hline \multirow{24}{*}{ Occupation } & \multirow{2}{*}{ Student } & 24 & 51 & 5 \\
\hline & & $8.0 \%$ & $15.1 \%$ & $2.1 \%$ \\
\hline & \multirow{2}{*}{ Teacher/Education Staff } & 50 & 22 & 2 \\
\hline & & $16.6 \%$ & $6.5 \%$ & $0.8 \%$ \\
\hline & \multirow{2}{*}{ House Keeper } & 2 & 6 & 0 \\
\hline & & $0.7 \%$ & $1.8 \%$ & $0.0 \%$ \\
\hline & \multirow{2}{*}{ Government Staff } & 31 & 16 & 21 \\
\hline & & $10.3 \%$ & $4.7 \%$ & $8.8 \%$ \\
\hline & \multirow{2}{*}{ Policy/Military } & 8 & 10 & 0 \\
\hline & & $2.7 \%$ & $2.9 \%$ & $0.0 \%$ \\
\hline & \multirow{2}{*}{ Medical/Bio Industry } & 27 & 16 & 0 \\
\hline & & $9.0 \%$ & $4.7 \%$ & $0.0 \%$ \\
\hline & \multirow{2}{*}{ Banking/Insurance } & 22 & 38 & 48 \\
\hline & & $7.3 \%$ & $11.2 \%$ & $20.0 \%$ \\
\hline & Media/Mass & 43 & 36 & 30 \\
\hline & Communication & $14.3 \%$ & $10.7 \%$ & $12.5 \%$ \\
\hline & House/Restate/ & 19 & 24 & 6 \\
\hline & Construction Industry & $6.3 \%$ & $7.1 \%$ & $2.5 \%$ \\
\hline & \multirow{2}{*}{ Other Service Industry } & 12 & 66 & 75 \\
\hline & & $4.0 \%$ & $19.5 \%$ & $31.3 \%$ \\
\hline & \multirow{2}{*}{$\begin{array}{l}\text { Other Manufacturing } \\
\text { Industry }\end{array}$} & 46 & 43 & 43 \\
\hline & & $15.3 \%$ & $12.7 \%$ & $17.9 \%$ \\
\hline & \multirow{2}{*}{ Others } & 17 & 10 & 10 \\
\hline & & $5.6 \%$ & $2.9 \%$ & $4.2 \%$ \\
\hline \multirow{10}{*}{$\begin{array}{l}\text { Annual } \\
\text { Income }\end{array}$} & \multirow{2}{*}{ Less than US\$16,000 } & 22 & 93 & 138 \\
\hline & & $7.3 \%$ & $27.5 \%$ & $57.5 \%$ \\
\hline & \multirow{2}{*}{ US\$ 16,000 - 31,999 } & 48 & 84 & 75 \\
\hline & & $15.9 \%$ & $24.9 \%$ & $31.3 \%$ \\
\hline & \multirow{2}{*}{ US\$ 32,000 - 47,999 } & 86 & 74 & 12 \\
\hline & & $28.6 \%$ & $21.9 \%$ & $5.0 \%$ \\
\hline & \multirow{2}{*}{ US\$ 48,000 - 63,999 } & 94 & 48 & 9 \\
\hline & & $31.2 \%$ & $14.2 \%$ & $3.8 \%$ \\
\hline & $\mathrm{U}$ & 51 & 39 & 6 \\
\hline & 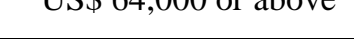 & $16.9 \%$ & $11.5 \%$ & $2.5 \%$ \\
\hline
\end{tabular}


Table 1. Basic data of the Turkish, Taiwanese, and Thai respondents (con.)

\begin{tabular}{|c|c|c|c|c|}
\hline & \multirow[t]{2}{*}{ Categories } & \multicolumn{3}{|c|}{$\begin{array}{c}\text { Number of Respondents } \\
\text { Percentage }\end{array}$} \\
\hline & & Turkey & Taiwan & Thailand \\
\hline \multirow{5}{*}{$\begin{array}{l}\text { Which } \\
\text { Browser } \\
\text { are you } \\
\text { mostly } \\
\text { using now }\end{array}$} & Google Chrome & $\begin{array}{c}126 \\
41.9 \% \\
\end{array}$ & $\begin{array}{c}213 \\
63.0 \% \\
\end{array}$ & $\begin{array}{c}148 \\
61.7 \% \\
\end{array}$ \\
\hline & Microsoft IE & $\begin{array}{c}87 \\
28.9 \% \\
\end{array}$ & $\begin{array}{c}70 \\
20.7 \% \\
\end{array}$ & $\begin{array}{c}38 \\
15.8 \% \\
\end{array}$ \\
\hline & Mozilla Firefox & $\begin{array}{c}46 \\
15.3 \%\end{array}$ & $\begin{array}{c}23 \\
6.8 \%\end{array}$ & $\begin{array}{c}41 \\
17.1 \%\end{array}$ \\
\hline & Opera Software Opera & $\begin{array}{c}0 \\
0.0 \% \\
\end{array}$ & $\begin{array}{c}12 \\
3.6 \% \\
\end{array}$ & $\begin{array}{c}1 \\
0.4 \% \\
\end{array}$ \\
\hline & Apple Safari & $\begin{array}{c}42 \\
14.0 \%\end{array}$ & $\begin{array}{c}20 \\
5.9 \%\end{array}$ & $\begin{array}{c}12 \\
5.0 \%\end{array}$ \\
\hline
\end{tabular}

Table 1 illustrates that demographic profile of respondents and which browser they use the most. The sample had more male than female respondents. In Turkey, there were 154 male (51.2\%) and 147 female (44.8\%) respondents. In Taiwan, 172 (50.9\%) respondents were male and $166(49.1 \%)$ were female. In Thailand, $133(55.4 \%)$ respondents were male and $107(44.6 \%)$ were female. Table 1 shows that most respondents used Google Chrome, followed by Microsoft Internet Explorer, Mozilla Firefox, Apple Safari, and Opera Software Opera. Most respondents in three countries had at least a bachelor's degree, and respondents aged 20-45 were more likely to fill out the questionnaire. To examine the hypothesis, a PLS path analysis was used because it is a regression-based technique capable of simultaneously analyzing structure models with multiple-item constructs and structural path coefficients. ${ }^{16,32}$

\section{DATA ANALYSIS AND IMPLICATIONS}

Smart PLS, one of the leading software tools for PLS SEM analysis was used to generate the results presented in Tables 2-4. Table 2 shows that all factors in the measurement model exhibited adequate reliability and convergent validity because all factor loadings were greater than 0.7 , the composite reliabilities exceeded the acceptable criteria of 0.6 , and the average variances extracted (AVE) were greater than the threshold value of 0.5 in all cases. In Table 3, the diagonal elements represent the square roots of AVE, and the off-diagonal elements are the correlations between constructs. All diagonal elements are higher than the off-diagonal elements in the corresponding rows and columns; thus, discriminant validity exists. 
Table 2. Reliability and convergent validity of constructs

\begin{tabular}{|c|c|c|c|c|}
\hline Constructs & Items & $\begin{array}{c}\text { Factor } \\
\text { Loading }\end{array}$ & $\begin{array}{l}\text { Composite } \\
\text { Reliability }\end{array}$ & AVE \\
\hline \multirow{4}{*}{ Satisfaction } & S1 & 0.809 & \multirow{4}{*}{0.855} & \multirow{4}{*}{0.811} \\
\hline & $\mathrm{S} 2$ & 0.833 & & \\
\hline & S3 & 0.866 & & \\
\hline & S4 & 0.835 & & \\
\hline \multirow{4}{*}{ Preference } & $\mathrm{P} 1$ & 0.704 & \multirow{4}{*}{0.731} & \multirow{4}{*}{0.806} \\
\hline & P2 & 0.799 & & \\
\hline & P3 & 0.742 & & \\
\hline & P4 & 0.808 & & \\
\hline \multirow{4}{*}{ Familiarity } & F1 & 0.707 & \multirow{4}{*}{0.832} & \multirow{4}{*}{0.775} \\
\hline & $\mathrm{F} 2$ & 0.885 & & \\
\hline & F3 & 0.868 & & \\
\hline & $\mathrm{F} 4$ & 0.889 & & \\
\hline \multirow{4}{*}{ Experience } & E1 & 0.853 & \multirow{4}{*}{0.836} & \multirow{4}{*}{0.722} \\
\hline & E2 & 0.864 & & \\
\hline & E3 & 0.827 & & \\
\hline & E4 & 0.739 & & \\
\hline \multirow{4}{*}{ Attraction } & A1 & 0.870 & \multirow{4}{*}{0.877} & \multirow{4}{*}{0.855} \\
\hline & A2 & 0.858 & & \\
\hline & A3 & 0.836 & & \\
\hline & A4 & 0.855 & & \\
\hline \multirow{4}{*}{$\begin{array}{l}\text { Switching } \\
\text { Intention }\end{array}$} & SI1 & 0.809 & \multirow{4}{*}{0.903} & \multirow{4}{*}{0.864} \\
\hline & SI2 & 0.900 & & \\
\hline & SI3 & 0.916 & & \\
\hline & SI4 & 0.905 & & \\
\hline
\end{tabular}

Table 3. Discriminant examination of the constructs

\begin{tabular}{lcccccc}
\hline & Satisfaction & Preference & Familiarity & Experience & Attraction & Intention \\
\hline Satisfaction & 0.901 & & & & & \\
Preference & 0.484 & 0.898 & & & & \\
Familiarity & 0.360 & 0.518 & 0.880 & & & \\
Experience & 0.544 & 0.618 & 0.580 & 0.850 & & \\
Attraction & 0.375 & 0.605 & 0.577 & 0.650 & 0.925 & \\
Intention & -0.262 & -0.348 & -0.249 & -0.394 & -0.327 & 0.930 \\
\hline
\end{tabular}


Table 4. The PLS results in three nations

\begin{tabular}{lllll}
\hline & $\begin{array}{c}\text { Dependent } \\
\text { Variable }\end{array}$ & \multicolumn{3}{c}{ Switching Intention } \\
\cline { 3 - 5 } $\begin{array}{l}\text { Independent } \\
\text { Variable }\end{array}$ & $\begin{array}{c}\text { Turkish } \\
\text { respondents }\end{array}$ & $\begin{array}{c}\text { Taiwanese } \\
\text { respondents }\end{array}$ & $\begin{array}{c}\text { Thai } \\
\text { respondents }\end{array}$ \\
\hline Satisfaction & $\mathrm{R}^{2}$ Adjusted & $0.374^{* * *}$ & $0.425^{* * *}$ & $0.341^{* * *}$ \\
Preference & 0.043 & 0.102 & 0.046 \\
Familiarity & $0.164 *$ & $0.465^{* * *}$ & $0.401 * * *$ \\
Experience & 0.123 & 0.091 & 0.025 \\
Attraction & $0.431^{* * *}$ & $0.337 * * *$ & $0.334 * * *$ \\
\hline
\end{tabular}

Note: * represents $p<0.05$, ** represents $p<0.01$, *** represents $p<0.001$

As shown in Table 4, the $\mathrm{R}^{2}$ adjusted were $0.374,0.425$, and 0.341 for the Turkish, Taiwanese, and Thai respondents, respectively. These results show that neither satisfaction nor familiarity significantly influenced switching intention among respondents in any country, but preference, experience, and attraction all did. Hypotheses 1 and 3 might have been rejected because service satisfaction differs little among web browsers and because most people know how to use a web browser to surf the Internet. Hypotheses 4 and 5 were supported at the significance level of $p$-value $<0.001$, revealing that the attractiveness of current browsers and experience of users with their current browser considerably affected intention to switch browsers.

Table 4 also shows that the influence of preference differed among the three respondent groups, with $p$-value $<0.05$ for the Turkish respondents and $p$-value $<0.001$ for the Taiwanese and Thai respondents. These results imply that preference had a marginal significant effect on Turkish users' switching intention whereas it had a highly significant effect on the Taiwanese and Thai users' intention to switch browsers. By considering satisfaction as the push effect, the preference, familiarity, and experience as the mooring effect, and the attraction as the pull effect, the effect of mooring factor (preference plus experience) has the strongest influence on each nation's users, especially for Taiwanese and Thai users.

By analyzing surveys completed by 879 Internet users in Turkey, Taiwan, and Thailand, this study empirically confirmed that PPM is useful in explaining consumer switching intention in the context of online services. This finding is consistent with Zengyan et al. ${ }^{12}$, Hou et al., ${ }^{13}$ Ye and Potter ${ }^{2}$, Zhang et al., ${ }^{15}$ and Hsieh et al.. ${ }^{16}$ The results also show that user's experience was a significant factor; this is consistent with Kim et al. ${ }^{10}$ and Zengyan et al.. ${ }^{12}$ In contrast, the pull effect (attraction) is the most powerful factor in the study of Kim et al., ${ }^{10}$ the push effect holds the highest influence 
in the study of $\mathrm{Li}$ et al ${ }^{11}$ and the mooring effect exerts no effect on switching intention in the study of Zengyan et al.. ${ }^{12}$ This study supported the conclusion of Hou et al. ${ }^{13}$ that the mooring effect is the strongest driver of switching intentions.

In contrast to Ye and Potter ${ }^{2}$ and Zhang et al. ${ }^{15}$ who concluded that pushing, pulling, and mooring are all significant factors influencing user intention to switch, this study is consistent with Zengyan et al. ${ }^{12}$ and Hou et al. ${ }^{13}$ in contending that only two of these three factors exert significant influence. As noted, this study shows that satisfaction was not a significant factor affecting the intention to switch web browsers for Turkish, Taiwanese, and Thai Internet users, which is in contrast to conclusions from the literature in offline services, ${ }^{33,34,35}$ mobile telecommunication services,${ }^{29}$ and even online services. ${ }^{2,8,10,11,15,23}$

In explaining this inconsistency, this study notes that retail banking services was the subject of studies by Bansal and Taylor, ${ }^{33}$ Ganesh et al., ${ }^{34}$ and Athanassopoulos. ${ }^{35}$ Keaveney and Parthasarathy, ${ }^{8}$ Kim et al., ${ }^{10} \mathrm{Li}$ et al., ${ }^{11}$ Shin and Kim, ${ }^{29}$ Zhang et al. ${ }^{23}$ Zhang et al., ${ }^{15}$ Wu et al., ${ }^{17}$ and Liu ${ }^{18}$ examined paid computer online service, email service, e-commerce websites, mobile telecommunication service, blog service platforms, blog service providers, SNSs, and online trading platforms, respectively. However, Ye and Potter ${ }^{2}$ also chose web browser services as their topic and concluded that pushing, pulling, and mooring are all significant factors in user intention to switch. This study, however, discovered that only pull and mooring effects are significant factors and push effect (satisfaction) is not. The different result in the push effect is attributable to the following reasons:

(1) Ye and Potter ${ }^{2}$ collected 414 usable responses from 637 students in two classes at a State university. By contrast, this study collected 879 valid responses from respondents in different countries and from a range of occupations, ages, incomes, and education levels. Therefore, these demographic variables may affect consumer switching intention.

(2) Notably, there is a seven-year interval between Ye and Potter's ${ }^{2}$ survey and this one. Ye and Potter found that the service quality mainly affected the satisfaction, and explained why satisfaction significantly impacted the switching intention. With the rapid advance of Internet and information technology, the service quality provided by web browsers may have greatly improved in the intervening seven years. Hence, the service quality provided by current main web browsers may not be differentiated by most users. 
By analyzing the surveys completed by the 879 respondents in Turkey, Taiwan and Thailand, this study concluded that satisfaction (a push factor) did not exert the expected effect in user intention to switch web browsers, even though it exerted a significant influence on consumer switching intention for email service, e-commerce websites, blog platforms, and online communities. According to the proceeding analysis, there are two possible reasons for this unexpected result:

(1) People use web browsers to access other Internet services. Web browser providers may offer many services, but respondents rarely use them, and this proportion is nearly identical among different web browsers. Since users take advantage of only a small portion of browser services, they cannot tell which web browser service is superior.

(2) These competing web browsers look and behave similarly. Users could not differentiate the services offered by the most widely used web browsers, but they can distinguish those of other types of online services (e.g., blog platforms, video-sharing sites, and online banking). That is why Internet users report almost same level of satisfaction from competing web browser providers.

These findings have several implications. Most importantly, service satisfaction has been recognized as a crucial factor in many types of services, but it does not exert a significant influence on consumer switching between Web browsers. The reason is that people use web browsers simply to access other Internet-based services. Therefore, web browser providers are advised to promote all their service functions and execute a strategy to encourage consumers to try a variety of them. Once consumers use these services, they may be able to evaluate and distinguish web browser providers, resulting in different levels of satisfaction or dissatisfaction. In doing so, service satisfaction might become a significant factor in consumer switching between web browsers, as long as consumers use many service items instead of just the World Wide Web.

In contrast to satisfaction (a push factor) having no significant influence in the three countries, both experience and attraction considerably influenced respondents' intention to switch web browsers at the significant level of $p$-value $<0.001$. Preference exerted a significant influence on consumer switching intention between web browsers in Turkey at $p$-value $<0.05$ and in both Thailand and Taiwan at $p$-value $<0.001$. Therefore, whether users switched from one web browser to another did not depend on the push factor but it did depend on the mooring factor (e.g., experience and preference) and the pull factor (e.g., attraction). This may explain why even though Microsoft used a lock-in strategy when bundling 
its Windows operating system with Internet Explorer or Edge, Google Chrome beat Microsoft Internet Explorer. Google Search is the default search engine in Google Chrome, which many users prefer. The efficiency and brand impression of Google Search are impressive to consumers, increasing the attractiveness of Google Chrome. Therefore, the appealing features of a web browser can draw users away from its rivals, whereas the unique attractiveness of competing browsers can result in the loss of current users. At the same time, a positive experience may make users reluctant to switch to another web browser.

Table 4 shows that familiarity had no significant influence on Turkish, Taiwanese, and Thai users' switching intention. Therefore, in contrast to the finding that experience and attraction hold the most crucial influence for consumers' intention to switch web browsers, satisfaction and familiarity are less important. This may explain the success of Microsoft Internet Explorer's use of a bundled free strategy with the Windows operating system to defeat Netscape Navigator, which accounted for $90 \%$ of all web use at its peak. That is, although people were familiar with Netscape Navigator and satisfied with its service, Microsoft Internet Explorer's bundled free strategy brought a more positive experience. Accordingly, the implication is that whether consumers switch from one web browser to another depends not on service satisfaction (a push factor) but rather on mooring and push factors. Therefore, enhancing the browser's attractiveness and consumers' positive experiences are key success strategies in the market of web browsers.

Table 4 reveals that preference had a significantly higher influence for Thai and Taiwanese Internet users than for their Turkish counterparts. Because both experience and preference are mooring factors, the mooring factor exerts a greater influence in Thailand and Taiwan than in Turkey. Therefore, enhancing current users" "preference and experience" is a more effective strategy in the Thai and Taiwanese market than in the Turkish market. Another implication is that retaining current users may be more important than attracting users from competitors in Thai and Taiwan because the effect of retaining users is higher than obtaining potential users when compared to the effect of mooring factor (preference plus experience) to the effect of pull factor (attractiveness) in three countries. Conversely, in Turkey, the effect of retaining users is only slightly higher than that of obtaining new users when spending the same amount of effort and resources. Therefore, web browser providers in the Turkish market might put equal efforts and resources into retaining current users and attracting potential ones. However, web browser providers in Thai and Taiwanese market might spend more effort and resources on retaining current users 
than on attracting potential ones.

To examine the influence of demographics on browser switching intention, this study used five demographic variables (gender, age, education, occupation, and income) as independent variables and switching intention as the dependent variable. Through linear regression analysis via SPSS software, the results show that neither education nor occupation significantly influenced switching intention in any of the three countries. Furthermore, income only significantly influenced switching intention among the Taiwanese respondents (at the significant level of $p$-value $<0.001)$, gender and age only significantly influenced switching intention among the Turkish respondents (at $p$-value $<0.01$ and $p$-value $<0.05$, respectively). Notably, none of the five demographic variables significantly influenced switching intention among the Thai respondents. Therefore, the influence of demographics on switching intention in web browser market may vary across countries.

\section{DISCUSSION}

As discussed in the literature review, the identified factors affecting users' switching intention can vary across studies having the same theoretical basis (i.e., PPM). The conflicting and inconsistent findings of these studies can be attributed to the different contexts of web services. For example, in the context of online broker services, Chen and $\mathrm{Hitt}^{9}$ identified that switching cost and the ability to develop customer loyalty are key determinants. In terms of email services, Kim et al. ${ }^{10}$ identified the attractiveness of alternatives was identified as the most influential factor. In buyer-seller online business services, $\mathrm{Li}$ et al. ${ }^{11}$ concluded that satisfaction is the most influential factor. In the context of online games, Hou et al. ${ }^{13}$ revealed that the mooring factor is the most critical factor, in contrast to Zengyan et al. ${ }^{12}$ who determined that this factor is an influential factor. In online auction services, Lin et al. ${ }^{14}$ discovered that switching costs and transaction costs are the most crucial. Regarding SNS, Wu et al. ${ }^{17}$ observed that switching barriers and satisfaction are the most influential factors. Regarding blogging sites, both Zhang et al. ${ }^{15}$ and Hsieh et al. ${ }^{16}$ demonstrated that push, pull and mooring factors all play significant roles in users' switching intention. In the e-trading of securities, Liu et al. ${ }^{18}$ found that perceived value, satisfaction and e-trust are crucial factors. In web browser services, Ye and Potter ${ }^{2}$ discovered that habit is a significant factor; by contrast, the present study revealed that preference is an influential factor.

The preceding discussion implies that the crucial factors influencing 
users' switching intention vary across website service contexts. We call this phenomenon the contextual effect. This means that users in different website service contexts may have different perceptions, expectations or priorities. Web browser providers can thus benefit from research focusing on the context of web browsers rather than other online service contexts because a strategy that is effective in one certain online service context may not always be effective in others. If the marketers want to retain their users and prevent them from switching to competitive web browsers, this research thus can offer them the most useful clues. In sum, marketers would be wise to devise service features subject to context-specific or segment-specific users' priorities.

The difference between $\mathrm{Ye}$ and Potter $^{2}$ and the present study is discussed in the previous section. Both Ye and Potter $^{2}$ and the present study demonstrated that the pull and mooring effects significantly influence switching intention. Notably, Ye and Potter ${ }^{2}$ reported that habit significantly influences the intention to switch, but this study found that user preference is a significant factor in user switching intention in varying degrees across countries ( $p$-value $<0.05$ for Turkey and $p$-value $<0.001$ for Taiwan and Thailand). Specifically, preference had a marginally significant effect on Turkish users' switching intention and a highly significant effect on the Taiwanese and Thai users' intention to switch browsers. Because Ye and Potter $^{2}$ conducted their study in the United States, while this study was based on surveys in Turkey, Taiwan and Thailand, the influences of user habit or preference in the context of web browsers may vary. In contrast, the pull and mooring factors have considerably affected users' switching intention in the context of web browsers.

By surveying 301 respondents in Turkey, 338 respondents in Taiwan, and 240 respondents in Thailand, the results revealed that user experience and attractiveness, but not satisfaction or familiarity, influence user intention to switch web browsers. Ye and Potter ${ }^{2}$ suggested that web browser use is often highly ingrained in daily routines; thus, they proposed that habit may be crucial in influencing users' switching intention. In contrast, the results of the current study suggested that web browser use is highly ingrained in daily routines because of user preferences, and then user preferences create habits that form daily routines.

Moreover, since neither satisfaction nor familiarity significantly influenced switching intention among the respondents in any country while experience, attraction, and preference considerably influenced switching intention in all three countries, web browser providers should direct their resources into enhancing their browser's appealing features and users' positive experience. In other words, attracting new users to a web browser 
relies on attractiveness, but retaining those users relies on delivering a positive experience.

The level of influence of experience, attraction, and preference on the switching intention of users across the three countries is listed in Table 4. Table 4 reveals that web browser developers in Turkey should offer appealing features to draw potential users from competing web browsers and enhance current users' positive experience by continuously improving all aspects of the browser. In Turkey, the effect of putting efforts and resources to reduce switching opportunities of a web browser's current users is equal to increase potential users of using a web browser's opportunities. This is because the effect of retaining current users is very close to attracting competitors' users when spending the same amount of effort and resources. In contrast, web browser developers in Taiwan and Thailand should devote their resources to servicing current users instead of drawing potential users from competing web browsers. This is because the effect of gaining competitors' users is lower than that of retaining existing users when spending the same amount of effort and resources.

\section{CONCLUSIONS}

The Internet is a global communication network that originated in the 1960s and was commercialized in the 1990s. Abundant research has studied commercial Internet-based services over the past two decades but only one study has investigated web browsers. The present research not only fills this gap but also offers researchers and practitioners fresh insights into the marketing of other free-to-use and registration-free Internet-based services, such as instant messengers, mobile application services (apps), and open service software or platforms. Through a cross-national survey of 879 respondents, this study empirically identified that browser attractiveness, positive user experience, and user preference are the main determinants of success in the web browser market.

Moreover, compared with studies on other types of service markets, this study yielded an unexpected but interesting finding: because web browsers are free and have little to no switching cost or lock-in effect, they are characterized by high substitutability and low differentiation, and have only slight brand value. Because web browser exhibits characteristics distinct from those of other online services (i.e., e-banking services, e-mail services, e-commerce websites, blog platforms, shopping websites, and online communities), caution must be exercised when generalizing the current findings to other online services. Besides, although this study observed contextual effects, more detailed empirical studies are required to 
examine this phenomenon.

Although this study advances current knowledge on the factors affecting user intention to switch web browsers, offers international viewpoints on the topic, and provides web browser providers some cues for strategically optimizing their efforts on the push, pull, and mooring dimensions, some limitations should be considered when interpreting the results of the study. First, because of limited manpower and resources, online questionnaires were administered to survey respondents. Because bias naturally exists in any questionnaire-based survey, future studies should be both quantitative and qualitative. Web browser providers can use face-to-face interviews and web mining to collect more in-depth, comprehensive, and precise data to devise user-retention strategies. In addition, when conducting cross-national surveys in the future, researchers should collect samples reflecting the proportions of the populations of the countries under consideration.

Compared with the extensive research on switching intention for offline services and other online services, research on user switching intention regarding web browsers is scant. Hence, more empirical research is necessary to re-examine the current findings, particularly because the web browser market is unique among online services. Another limitation is that this study investigated only the respondents' switching intention, not their behavior. Thus, future studies should investigate web browser switching behavior. Statistics show that most consumers today engage in multiscreen behavior: $90 \%, 80 \%$, and $47 \%$ of global Internet users access the Internet from a PC or notebook, a mobile phone, or a tablet, respectively. ${ }^{36}$ Therefore, in addition to investigating switching intention for desktop browsers, switching intention for mobile browsers is also worthwhile investigated.

Finally the term "switching" implies the abandonment of one service provider for another. However, in practice, people often use several competing services, such as credit cards, e-banking, and mobile payments, at the same time. Similarly, people who use Google Chrome may still use Internet Explorer when visiting some websites that support only that browser. In this study, switching was defined as primarily using a new web browser and rarely using a previous one. Further research could use click-stream data instead of a questionnaire to measure switching. This study examined only five factors in consideration of the balance between the predictive power and parsimony of the model. Other factors such as social influence and the working environment are also worth investigation. 


\section{REFERENCES}

[1] Internet World Stats, World Internet usage and population statistics. 2016. Retrieved on December 23, 2016, from http://www.internetworldstats.com/.

[2] C. Ye, and R. Potter, The role of habit in post-adoption switching of personal information technologies: An empirical investigation. Communications of the Association for Information Systems, 28(35), p585-610, 2011.

[3] MakeUseOf, Browser War: Firefox vs. Chrome vs. Opera, the definitive benchmark. Retrieved on December 25, 2016, from http://www.makeuseof.com/tag/browser-wars-firefox-vs-chrome-vsopera-definitive-benchmark/

[4] IT World Canada, Should Microsoft give up on browser war? Retrieved on December 25, 2016, from http://www.itworldcanada.com/blog/ should-microsoft-give-up-on-browser-war/ 388996

[5] StatCounter Global States, Top browsers per countries. Retrieved on December 25, 2016, from http://gs.statcounter.com/\#all-browser-wwmonthly-201608-201608-bar

[6] Net Market Share, Market Share Report: Desktop Top Browser Share Trend. Retrieved on April 30, 2017, from https://www.netmarketshare.com/.

[7] S. M. Keaveney, Customer switching behavior in service industries: An exploratory study. Journal of Marketing, 59(2), p71-82, 1995. http://dx.doi.org/10.2307/1252074

[8] S. M. Keaveney, and M. Parthasarathy, Customer switching behavior in online services: An exploratory study of the role of selected attitudinal, behavioral, and demographic factors. Academy of Marketing Science, 29(4), p374-390, 2001. http://dx.doi.org/10.1177/03079450094225

[9] P. Y. Chen, and L. M. Hitt, Measuring switching costs and the determinants of customer retention in Internet-enabled businesses: A study of the online brokerage industry. Information Systems Research, 13(3), p255-274, 2002. http://dx.doi.org/10.1287/isre.13.3.255.78

[10] G. Kim, B. Shin, and H. G. Lee, A study of factors that affect user intentions toward email service switching. Information \& Management, 43(4), p884-893, 2006. http://dx.doi.org/10.1016/j.im.2006.08.004

[11] D. Li, G. J. Browne, and J. C. Wetherbe, Online consumers' switching behavior: A buyer-seller relationship perspective. Journal of Electronic Commerce in Organizations, 5(1), p30-42, 2007.

[12] C. Zengyan, Y. Yinping, and J. Lim, Cyber migration: An empirical investigation on factors that affect users' switch intentions in social networking sites, Paper presented at the 42nd Hawaii International 
Conference on System Sciences (HICSS), Hawaii, USA, January 5-8, 2009. doi: 10.1109/HICSS.2009.140.

[13] A. C. Y. Hou, C. C. Chern, H. G. Chen, and Y. C. Chen, Migrating to a new virtual world: Exploring MMORPG switching through human migration theory. Computers in Human Behavior, 27(8), p1892-1903, 2011. http://dx.doi.org/10.1016/j.chb.2011.04.013

[14] T. C. Lin, H. K. Cheng, F. S. Wang, and K. J. Chang, A study of online auction sellers' intention to switch platform: The case of Yahoo!Kimo versus Ruten_eBay. Decision Sciences, 43(2), p241-272, 2012.

[15] K. Z. K. Zhang, C. M. K. Cheung, and M. K. O. Lee, Online service switching behavior: The case of blog service providers. Journal of Electronic Commerce Research, 13(3), p184-197, 2012.

[16] J. K. Heieh, Y. C. Hsieh, H. C. Chiu, and Y. C. Feng, Post-adoption switching behavior for online service substitutes: A perspective of the push-pull-mooring framework. Computers in Human Behavior, 28(5), p1912-1920, 2012. https://doi.org/10.1016/j.chb.2012.05.010

[17] Y. L. Wu, Y. H. Tao, C. P. Li, S. Y. Wang, and C. Y. Chiu, User-switching behavior in social network sites: A model perspective with drill-down analyses. Computer in Human Behavior, 33(1), p92-10, 2014. http://dx.doi.org/10.1016/j.chb.2013.12.030

[18] C. H. Liu, The impact on switching intention of e-trading systems for the securities industry. Global Journal of Business Research, 9(1), p75-88, 2015.

[19] J. M. Curran, and M. L. Meuter, Self-service technology adoption: comparing three technologies. Journal of Services Marketing, 19(2), p103-113, 2005. https://doi.org/10.1108/08876040510591411

[20] H. S. Bansal, S. F. Taylor, and Y. S. James, "Migrating" to new service providers: Toward a unifying framework of consumers' switching behaviors. Academy of Marketing Science, 33(1), p96-115, 2005. https://doi.org/10.1177/0092070304267928

[21] C. S. Yu, Applying expectation-confirmation theory to probe what influences online banking continuance. Journal of Information Management, 17(3), p155-180, 2010.

[22] W. L. Shiau, and P. Y. K. Chau, Understanding blog continuance: A model comparison approach. Industrial Management and Data Systems, 112(4), p663-682, 2012. http://dx.doi.org/10.1108/02635571211225530

[23] K. Z. K. Zhang, M. K. O. Lee, C. M. K. Cheung, and H. Chen, Understanding the role of gender in bloggers' switching behavior. Decision Support Systems, 47(4), p540-546, 2009. https://doi.org/10.1016/j.dss.2009.05.013

[24] S. G. Nimako, and B. A. Ntim, Construct specification and misspecification within the application of Push-Pull-Mooring Theory 
of switching behavior. Journal of Business and Management Sciences, 5(1), p83-95, 2013

[25] C. S. Yu, What influences people to continuously use Web-based services? Paper Presented at the 18th International Conference on Information Management (ICIM), Taipei, Taiwan, May 26, 2007.

[26] N. Ahmad, A. Omar, and T. Ramayah, Consumer lifestyles and online shopping continuance intention. Business Strategy Series, 11(4), p227-243, 2010. http://dx.doi.org/10.1108/17515631011063767

[27] D. J. Bogue, Principles of Demography. New York: John Wiely, 1969.

[28] B. Moon, Paradigms in migration research: exploring "moorings" as a schema. Progress in Human Geography, 19(4), p504-524, 1995. http://dx.doi.org/10.1177/030913259501900404

[29] D. H. Shih, and W. Y. Kim, Mobile number portability on customer switching behavior: In the case of the Korean mobile market. The Journal of Policy, Regulation and Strategy for Telecommunications, Information and Media, 9(4), p38-54, 2007.

[30] M. S. Awwad, and B. A. Neimat, Factors affecting switching behavior of mobile service users: The case of Jordan. Journal of Economic and Administrative Sciences, 26(1), p27-51, 2010.

[31] N. Hermes, E. Kihanga, R. Lensink, and C. Lutz, The impact of trade credit on customer switching behaviour: Evidence from the Tanzanian rice market. Journal of Development Studies, 48(3), p363-376, 2012. http://dx.doi.org/10.1080/00220388.2011.615921

[32] C. S. Yu, Using e-lifestyle to analyze mobile banking adopters and non-adopters. Journal of Global Information Technology Management, 18(3), p188-213, 2015. http://dx.doi.org/10.1080/1097198X.2015. 1070619

[33] H. S. Bansal, and S. F. Taylor, The service provider switching model: A model of consume switching behavior in the service industry. Journal of Service Research, 2(2), p200-218, 1999. http://dx.doi.org/10.1177/109467059922007

[34] J. Ganesh, M. J. Arnold, and K. E. Reynolds, Understanding the customer base of service providers: an examination of the difference between switchers and stayers. Journal of Marketing, 64(3), p65-87, 2000. http://dx.doi.org/10.1509/jmkg.64.3.65.18028

[35] A. D. Athanassopoulos, Customer satisfaction cues to support market segmentation and explain switching behavior. Journal of Business Research, 47(3), p191-207, 2000. http://dx.doi.org/10.1016/ S0148-2963 (98) 00060-5

[36] Smart Insights, Mobile Marketing Statistics compilation. Retrieved on December 23, 2017, from http://www.smartinsights.com/mobilemarketing/mobile-marketing-analytics/mobile-marketing-statistics/ 


\section{APPENDIX}

\section{Questionnaire}

\section{Section 1}

Which Browser are you mainly using now?

$\square$ Google Chrome

$\square$ Microsoft Internet Explorer or Edge

$\square$ Mozilla Firefox

$\square$ Opera Software Opera

$\square$ Apple Safari

\section{Section 2}

All questions were culled from literature and assessed on a five-point Likert scale ranging from 1 (strongly disagree) to 5 (strongly agree). Their statements are described as follows:

\section{Satisfaction}

S1: I am satisfied with the speed provided by the bowser that I use most. S2: I am satisfied with the security provided by the bowser that I use most.

S3: I am satisfied with the response provided by the bowser that I use most.

S4: I am satisfied with the functionality provided by the bowser that I use most.

\section{Preference}

P1: Although I am aware of some criticism of this browser, it is still my main browser.

P2: I prefer using this browser rather than others.

P3: Considering that all browsers can always improve, I think this bowser is the best at present.

P4: I feel comfortable using this browser.

\section{Familiarity}

F1: I used to use this browser to surf the web.

F2: Compared with other browsers, I am most familiar with this browser's settings.

F3: Compared with other browsers, I am most familiar with this browser's features.

F4: Compared with other browsers, I am most familiar with this browser's interface.

\section{Experience}

E1: Using this browser is very easy. 
E2: Using this browser is very convenient.

E3: Using this browser is to access and browse information is a positive experience.

E4: I have experienced almost no trouble using this browser over the years.

\section{Attraction}

A1: Compared with other browsers, this browser appeals to me the most.

A2: Compared with other browsers, I like to use this browser.

A3: Compared with other browsers, this browser will attract more and more users.

A4: Compared with other browsers, using this browser is the best choice.

\section{Switching Intention}

SI 1: I will use another browser instead of continually using this browser.

SI 2: I intend to switch browsers within the next year.

SI 3: I plan to use another browser in recent one year.

SI 4: I predict that I will switch browsers within the next year.

\section{Section 3}

Five questions are used to collect respondents' basic data

1. Gender: $\square$ Male $\square$ Female

2. Age: $\square$ below $20 \square 20 \sim 25 \square 25 \sim 30 \square 30 \sim 35 \square 35 \sim 40 \square 40 \sim 45$

$$
\square 45 \sim 50 \quad \square 50 \sim 55 \square 55 \sim 60 \square 60 \sim 65 \square \text { above } 65
$$

3. Education: $\square$ High School or below $\square$ Associate Bachelor Degree

$\square$ Bachelor Degree $\square$ Master Degree $\square$ Ph.D. Degree

4. Occupation : $\square$ Student $\square$ Teacher/Education Staff $\square$ House Keeper

$\square$ Government Staff $\square$ Police or Military

$\square$ Medical or Bio Industry $\square$ Banking or Insurance

$\square$ Media or Mass Communication

$\square$ House, Restate, Construction Industry

$\square$ Other Service Industry $\square$ Other Manufacturing Industry

$\square$ Others

5. Annual Income (NT\$) : $\square 0 \sim 499,999 \square \square$ 500,000 999,999

$\square 1,000,000 \sim 1,499,999 \quad \square 1,500,000 \sim 1,999,999$

$\square 2,000,000$ or above 
